\title{
The reaction of the Portuguese stock market to ISO 9000 certification
}

\author{
GABRIELA BEIRÃO \\ Faculty of Economics, Porto University \\ Telephone: 351225020857 E-mail: gbeirao@hotmail.com
}

\author{
JOSÉ SARSFIELD CABRAL \\ Department of Management and Industrial Engineering, Faculty of Engineering, Porto University, Rua \\ dos Bragas, 4050-123 Porto, Portugal \\ Telephone: 351222073650 Fax: 351222073659 E-mail: jacabral@fe.up.pt
}

\begin{abstract}
In the recent years the ISO 9000 standards has experienced an extraordinary success. The number of certifications is still increasing worldwide and it is expected that this trend will last. In fact, ISO 9000 certification has become an important factor for doing business in the global market. However, there are many contradictory opinions regarding the real benefits of the ISO registration. This paper contributes to this debate by empirically investigating the impact on the Portuguese stock market of achieving ISO 9000 certification. The analysis is based on the event study methodology. The findings suggest that the market positively anticipate the event. It is also detected a favourable effect in achieving an early registration within the sector or industry.

A financial performance analysis covering a 5-year period centred on the year of the ISO 9000 certification was also carried out. The results suggest that the ISO 9000 certification have a powerful cost effect, decreasing the operating performance and the profitability in the year following the certification. Apparently, companies need one more year to recover those costs.
\end{abstract}

Key Words: Quality systems, ISO 9000, certification, stock market analysis, financial analysis. 


\section{Introduction}

The implementation of the ISO 9000 standards is spreading worldwide. Both large and small companies have built their quality systems based on ISO 9000 standards. This movement is especially significant in Europe, which had, by the end of 1998, 61 percent of the total certificates (ISO Survey, 1999). However, the implementation and maintenance of ISO 9000 certification require the investment of considerable amounts of time and money.

The fundamental question addressed in this paper is whether the benefits of the ISO 9000 certification are enough to overcome the losses. To some extent, the question can be answered by measuring the impact of certification on the market value and by tracking the evolution of financial performance indicators (before and after certification). Notice that, although there is a vast literature addressing the pros and cons of ISO 9000, few empirical studies can be found addressing the impact of ISO 9000 certification on the market value (see, for instance, Docking and Dowen, 1999).

Therefore, two topics are considered regarding the effects of ISO 9000 certification. Firstly, the Portuguese stock market reaction to ISO 9000 certification is investigated by estimating abnormal returns around the day of the certification announcement. A positive reaction would indicate that certification provides valuable information to the market. The effect of the size of the company and the impact of an early registration is also analysed. Secondly, six financial performance indicators are examined over a period encompassing two years before and two years after the year when ISO 9000 certification is achieved. The results can provide information to management regarding the decision of implementing or not ISO 9000 systems.

\section{Expected benefits from ISO 9000 implementation and certification}

It is expected that managers act to maximise their company value. Accordingly, they will adopt a quality system based on ISO 9000 when they anticipate a positive investment (in terms of net present value). Notice that the amount of money and time involved can be substantial. For instance, the average time in Portugal for the entire certification process is about two years, although the length of that period depends on the size and maturity of the organisation. On the one hand, internal benefits can arise 
from the implementation of a quality system and, on the other hand, certification (or registration) can also convey other gains. In fact, ISO 9000 certification is a way of disclosing information to external parties. A certified quality system can help a company to enter in a market (but is not a guarantee that a company will actually receive new customers).

Several surveys and studies have been conducted to determine why companies seek ISO 9000 certification (European Commission, 1997; LRQA, 1994; Anderson et al., 1999). The results of these surveys pointed several external and internal reasons motivating companies to obtain certification. The European Commission Survey (1997) showed that the reasons for certifying the quality system were mostly related to external forces (pressure by customer, increase of competitive position, trend in the European market, marketing, major competitors are certified). Only one third seek certification for internal reasons (need for higher internal efficiency, need for improvement of the existing quality system). Although certification is not obligatory, it can be regarded as a condition to compete. Nevertheless, the need to comply with regulatory requirements (EU Directives) was mentioned by less than $2 \%$ as the main reason for certifying the quality system.

Many organisations have claimed benefits as a direct consequence of the implementation and certification of a quality system based on ISO 9000 series. It is important to distinguish between the benefits resulting from the implementation of a quality system from those of having it certified. The gains attained in each case are clearly distinct.

According to the European Commission Survey (1997), for the EU companies' the most important benefits of introducing a quality system are internal: improved quality awareness, clearer responsibilities, involvement of employees, improved internal efficiency, etc.

The benefits of certifying a quality system are mainly external and market related: ISO 9000 can produce impacts such us increasing customer confidence and improving image (European Commission Survey, 1997). The survey also reported that competitiveness is an important factor (despite it was not considered in the questionnaire).

A recent empirical research of a sample including 100 Italian firms (see Romano, 2000) concludes that the impact of certification is clearest in the areas of Quality (both 
internal and external and their related costs), punctuality, and throughput time, while there are no significant positive effects on other time and cost performance. As it can be seen, the ISO 9000 benefits are still a debatable matter.

\section{Hypothesises on the stock market reaction to IS00 9000 certification}

The extent to which the stock market reacts to an announcement like ISO 9000 certification depends on well the information contained in that announcement is anticipated. The information of the ISO 9000 certification may not be a complete surprise to the stock market because the company may have informed the market that it was implementing a quality system based on ISO 9000 standards. The stock market may have incorporated part of the value attributable to the quality system even before the company has certified it. In such cases, the stock market's reaction to achieving the ISO 9000 certification will understate the total value and will have little impact on market performance.

But, does the stock market consider the information contained in achieving ISO 9000 certification relevant? It is expected that investors react positively to ISO 9000 certification. On addition to the potential internal and external benefits, certification can also provide an independent judgement that gives confidence to the market that the company fulfils the requirements of a widely accepted international standard (thus demonstrating the capability to deliver products and services according to the customers' requirements). But, while an ISO certification may be valuable, this value is not the same across all firms, all firm sizes, and all industries (Docking and Dowen, 1999).

There are contradictory opinions about the consequences of ISO 9000 certification. The implementation of a quality system should aim at increasing the efficiency, productivity, and competitiveness of a company. But the certification process alone does not do this. Moreover, the costs associated with the implementation and certification of the ISO 9000 quality system are (relatively) large. Stock market investors may not believe that the internal and external benefits due to the implementation and certification of the quality system are sufficient to overweigh those additional costs. In this situation, achieving ISO 9000 certification would have a negative stock market reaction. Finally, investors may wait to see the company's 
performance, not reacting to ISO 9000 certification. The following hypotheses can then be stated:

$H_{0}$ : ISO 9000 certification (or registration) has no impact on the market value;

$H_{1}$ : ISO 9000 certification has a positive (or negative) impact on the market value.

If the null hypothesis is rejected in favour of a positive reaction, other interesting factors can also be investigated: the influence of the size of the company and the order in which the company receives the certificate amongst its competitors (in particular, being the first one within its sector).

\section{Testing the ISO 9000 impact on the market value: data and empirical method}

From the adoption of the ISO 9000 standards (back in 1988) until June 30, 1998, a total of 829 Portuguese companies have achieved ISO 9000 certification. Until that date, all the certifications were issued by the same agency, the APCER (the Portuguese Association for Certification). The initial sample consisted in fifteen companies, comprising all the registered firms whose stocks were listed in the Lisbon Stock Exchange. Unfortunately, two of them had to be excluded because they were only listed after being ISO 9000 certified. Therefore, the final sample considered in the study includes 13 companies. Stock prices and the BVL Geral index (the Lisbon stock market index) were obtained from the Lisbon Stock Exchange and were previously adjusted for dividend distribution or changes in the company's capital. The event or announcement date is the day when the ISO 9000 certificate is awarded to the company. The event dates were obtained from APCER. The daily returns were then computed in the logarithmic form.

Performing powerful tests regarding the announcement effect of the ISO 9000 certification presents some difficulties. One is the possibility that the event was anticipated or information leaked to the market in advance of the formal announcement. Other difficulty is the influence of confounding information. It's necessary to isolate these confounding events to determine the independent influence of ISO 9000 certification. All the 13 companies were checked in order to determine if any additional confounding events (like dividends, earnings) or other significant information was disclosed simultaneously. This scrutiny has not revealed any concurrent information disclosure. 
At the end, one company was excluded from the sample because its returns were not correlated to the market index used. Accordingly, the final sample contains only 12 companies with different sizes belonging to very distinct sectors (metallic and nonmetallic industry, chemical industry, food, paper, etc., including 9 distinct two-digit Economic Activity Classification - CAE - codes). Table 1 presents some statistics of the sample, referring to the year when the ISO 9000 certificate was awarded.

Table 1 - Sample statistics

The event study methodology was used to measure the effect of the ISO 9000 certification on stock prices (a complete description of this methodology can be found in Brown and Warner, 1985 and in Dyckman et al., 1984). The standard approach is based on estimating a market model for each company and then calculating abnormal returns. These abnormal returns are assumed to reflect the stock market's reaction to the announcement of new information. The returns are based on the market model, given by:

$$
R_{i t}=\alpha_{i}+\beta_{i} R_{m t}+\varepsilon_{i t},
$$

where $R_{i t}$ denotes the rate of return for stock $i$ for event day $t, R_{m t}$ is the rate of return on the $B V L$ Geral index on event day $t$, and $\varepsilon_{i t}$ is the error term of stock $i$ on event day $t$. In all cases it was not possible to reject the null hypothesis that the constant $\alpha$ was zero, so the final model adopted was $R_{i t}=\beta_{i} R_{m t}+e_{i t}$.

Daily abnormal returns are calculated, for each company, within a window of event time between $t=T_{1}$ and $t=T_{2}$, using:

$$
A R_{i t}=R_{i t}-\left(\hat{\alpha}_{i}+\hat{\beta}_{i} R_{m t}\right) .
$$

In this expression, $A R_{i t}$ denotes the abnormal return for company $i$ on day $t$, and $\hat{\alpha}_{i}, \hat{\beta}_{i}$ are ordinary least squares estimates of the market model parameters. The parameter estimation period includes 500 days, from $D_{1}=-520$ to $D_{2}=-21$. The ISO 9000 certification award day is denoted by day 0 in event time. For each event day $t=\left[T_{1}\right.$, $T_{2}$ ], the portfolio average abnormal return was obtained by:

$$
A A R_{t}=\frac{1}{N} \sum_{i=1}^{N} A R_{i t},
$$


$N$ being the number of companies included in the sample.

The cumulative average abnormal returns $(C A A R)$ was then computed by summing the $A A R$ over various time windows. In the absence of abnormal returns the expected values of $A A R$ and $C A A R$ are zero.

The tests statistics for $A A R$ and $C A A R$ are based on the standardised average abnormal return $\left(S A A R_{t}\right)$ and the standardised average cumulative abnormal return $\left(S C A A R_{T_{1}, T_{2}}\right)$, where

$$
S A A R_{t}=\frac{1}{N} \sum_{i=1}^{N} \frac{A R_{i t}}{S_{i t}}
$$

and

$$
S C A A R_{T_{1}, T_{2}}=\frac{1}{N} \sum_{i=1}^{N} \sum_{t=T_{1}}^{T_{2}} \frac{A R_{i t}}{S_{i t}},
$$

$S_{i t}$ being the company $i$ estimated standard variation, given by

$$
S_{i t}=\hat{s}_{i} \sqrt{1+\frac{1}{L_{i}}+\frac{\left(R_{m t}-\bar{R}_{m}\right)^{2}}{\sum_{d=D_{1}}^{D_{2}}\left(R_{m d}-\bar{R}_{m}\right)^{2}}}
$$

were,

$\hat{s}_{i}$ : estimated standard deviation of the abnormal returns of stock $i$ during the estimation period,

$L_{i}$ : number of trading days of the stock $i$ in the estimation period;

$R_{m t}:$ market return on day $t$ of the event period;

$\bar{R}_{m}$ : average market return during the estimation period;

$R_{m d}:$ market return for day $d$ of the estimation period.

The standardise cross-sectional test statistic developed by Boehmer et al. (1991) was used in order to test the hypothesis that the average standardise abnormal returns equal zero. This $t$-statistics is given by

$$
t=\frac{\frac{1}{N} \sum_{i=1}^{N} S A R_{i t}}{\sqrt{\frac{1}{N(N-1)} \sum_{i=1}^{N}\left(S A R_{i t}-\sum_{i=1}^{N} \frac{S A R_{i t}}{N}\right)^{2}}}
$$


where $S A R_{i t}$ is the stock $i$ 's standardise abnormal return for day $t$.

Finally, a non-parametric generalised sign test (see Cowan, 1992) examines whether the number of stocks with positive (or negative) abnormal returns in the event day exceeds the number expected in the absence of an abnormal performance. This location test is based on the normal approximation of the binomial distribution ( $Z$-statistics) and it is not affected by outlier returns in either a positive or negative direction.

\section{Empirical results}

Firstly, the market reaction to ISO 9000 certification was investigated by testing $H_{0}$. The test was performed using windows including event days on both side of the ISO 9000 registration date. The test of abnormal returns in days prior to the certification date makes sense. In fact, over the period covered by this study, the procedures adopted by APCER allow the market anticipation of the ISO 9000 award. After the final audit, whenever APCER reaches a favourable decision the company is formally informed (usually by fax) that the ISO 9000 certificate will be awarded. Some days latter (in general, within a month) the official certificate is issued. The certification date corresponds to this last day (and not to the day of the decision). According to this procedure a company could make public its achievement before the official announcement. In fact, it was observed that it is a common practice that companies inform their clients (and the market) after being notified by APCER, before the certification date.

Table 2 shows the average daily abnormal returns, the $t$-statistic, the percentage of positive abnormal returns, and the $Z$-statistic for a 11-day period ( -5 to +5 days in relation to the certification day). In the certification day $(t=0)$ the abnormal return is 0.082 percent, statistically insignificant at any conventional level $(t$-statistic $=0.632)$. However, for the -4 day the null hypothesis is rejected at the 5 percent level for both statistics. In fact, the -4 abnormal return is $0.478(t$-statistic $=2.804)$ with a percentage of 83.3 positive abnormal returns $(Z$-statistic $=2.208)$. 
Table 2 - Average abnormal returns (AAR) around ISO 9000 certification

The exercise was repeated using other windows and again a significant abnormal return was observed in the -4 day. These results can indicate that the market favourably anticipated the ISO 9000 certification.

Figure 1 presents the cumulative average abnormal returns for a 41-day period. None of the values was statistically significant at any conventional level. Yet, the figure shows an interesting pattern. The $C A A R$ gradually drifts up until day -16 and stays around values near 1 percent $(C A A R=1.189$ percent in day 0$)$. After day 9 the $C A A R$ gradually decrease to negative values to a minimum of $-0.64 \%(t=17)$. The $C A A R$ plot suggests that, to some extent, the market gradually learns about the forthcoming ISO 9000 award. The increasing positive pattern could reveal an anticipation of the market to the ISO 9000 certification.

Figure 1 - Cumulative average abnormal returns from event day -20 to event day +20

The $C A A R$ values were again calculated using various events time windows, but none of them were statistically significant.

\section{Checking the influence of the market value size and of an early certification}

The cumulative abnormal returns were regressed on three variables.

The first one was the market value size, because it is expected to be an important determinant of a stock's price reaction to ISO 9000 certification. Several studies (Docking and Dowen, 1999; Ramasesh, 1998; Hendricks and Singhal, 1996) show that the market reaction to news relating quality is only significant (or is stronger) for small companies. This effect was measured using the log of the market value size $(L M V)$. The variable $L M V$ is computed multiplying the price for the shares outstanding on the day of the ISO 9000 certification.

The order in which the companies achieve their ISO 9000 certification seems a possible determinant. If there is a favourable market reaction to ISO 9000 certification it will be a motivation for other companies to undertake the certification process. However, it is expected that, as time goes by, each new ISO 9000 certification is less newsworthy to the market. To capture these effects, two additional variables were defined. The variable $C E R T$, representing the order in which the announcement of the certification takes place 
for the companies in the sample (CERT can take value between 1 and 12 - the total number of firms included in the sample). In theory, this variable will have a positive relation to market returns if the certification adds value. The other variable, DCERT, measures the advantage of being the first company to register in a particular industry. $D C E R T$ is equal to 1 for any company that is the first to register within its two-digit CAE industry, and is 0 otherwise.

To test this relationships, cross sectional regression was performed using the standardised cumulative average abnormal return $(S C A A R)$ over the period $[-10,+1]$ as a dependent variable. That event window is based on the presumed market anticipation of the ISO 9000 certification. Using standardise returns diminish the effects of possible heteroskedasticity.

The regression results are shown in Table 3, indicating that the model has a relatively strong explanatory power (the $F$-statistic is significant at the 0.05 level and the adjusted $R$-squared is 54.4 percent). The coefficient of $L M V$ (logarithm of the market value size) is positive $(0.294)$ but not statistically significant. This result is consistent with the conjecture that ISO 9000 certification increases in value for all companies, independently of size.

The coefficient representing the order in which companies achieve ISO 9000 certification (variable CERT) has a positive sign (0.152) and is significant at the 0.01 level. The coefficient of DCERT is also positive (0.887) and statistically significant at the 0.05 level. These results suggest that the order in which the company achieves ISO 9000 certification is important. But contrary to Docking e Dowen (1999), it was found a positive relation between being the first in the industry to achieve ISO 9000 certification and the market reaction.

Table 3 - Cross-sectional regression of SCAAR $[-10,+1]$

\section{Long-term performance analysis}

It was mentioned that achieving ISO 9000 certification could have a positive impact on the internal efficiency and on the performance of the company. The objective of the analysis presented in this section is to measure the effect of ISO 9000 certification on the financial and sales performance of companies. Six financial ratios were considered to examine companies' performance over a period starting two years before ISO 9000 
certification and ending two years after. The financial performance measures are: sales per employee, sales to assets, operating income to sales, net income to sales, net income to assets, and, net income to shareholder's equity.

The sample is now different from the one used for the event study. In fact, from the 15 certified companies listed in the Lisbon Stock Exchange 7 were excluded. Three due to insufficient data, and four because they belong to economic sectors that have passed trough a recession showing strong negative values due to external factors (food products and beverage, and pulp, paper and paper products). The data was obtained from the published annual financial statements.

Table 4 lists the six financial performance ratios for the five years around the first ISO 9000 certification. Year 0 denotes the year of the first ISO 9000 certification, year 1 the subsequent year, and so on. The ratio sales per employee had a positive evolution over the five years, indicating an improving efficiency of the workforce. The other ratios drift down one year after ISO 9000 certification (year 1), but in year 2 they increased to values near the ones presented in year 0 . The evolutions of the last four performance ratios are also shown in Figure 2 (the first two ratios are expressed through very divergent value ranges, confusing their visual comparison).

Table 4 - Financial Ratios Around ISO 9000 Certification

Figure 2 - Evolution of the financial ratios

These results suggest that the ISO 9000 certification have a sound cost effect on companies, especially in the year following the certification. Those costs are covered in the next year, showing a rise in operating performance and profitability. Remark that only the ratios pattern is analysed and not its values, because not only the sample include companies from several sectors but also the value presented for each year corresponds to different calendar years.

The sample was divided according to the companies' industrial sector but the financial ratios showed a pattern similar to the one presented on Table 4.

The authors recognise that the long run performance cannot be attributed to ISO 9000 certification with an implication of a strict causality. However, if it is proved that, on average, the performance of the registered companies has improved in the years after 
achieving the ISO 9000 certification, a positive value of the ISO 9000 implementation and certification can be conjectured. A more rigorous analysis would involve finding matched pair companies, identical in all aspects except achieving the ISO 9000 certification. Unfortunately, due to the small dimension of the Portuguese stock market such study was not allowable.

\section{Conclusions}

In spite of the small size of the sample, there is some evidence suggesting that the Portuguese stock market react positively to ISO 9000 certification, indicating that certification convey good news about companies. The results show a statistically significant positive mean abnormal change in the stock prices four days before the announcement. Furthermore, the plot of the cumulative average abnormal returns showed a positive pattern from day -15 through day 9 . The study also reveals that, in addition to the advantage of an early certification, being the first in an industry to achieve certification seems to be important. Apparently, the size of the company is not related to the market reaction. Notice that, the positive stock market reaction is consistent with the theoretical and empirical research regarding the effect of implementing quality systems on the expected financial performance of companies.

In the second part of analysis, the financial ratios (sales to assets, operating income to sales, net income to sales, net income to assets, and, net income to shareholder's equity) showed a decrease one year after ISO 9000 certification, followed by a drift up in the subsequent year. Only the sales per employee ratio increase in all five years. The results suggest that ISO 9000 implementation and certification has costs, which are often high, but in the long-term the benefits overweigh the costs. This indicates that certification should be seen as a long-term investment. From an internal perspective, it takes time for organisations to fully capitalise the benefits of a quality system and make it work to their best advantage. External factors, such as an increased in market share, require several years to become evident in the company's accounting data. Thus, many benefits of ISO 9000 certification may occur after the 2-year period that was examined. Unfortunately, it was not possible to prolong the analysed years in this study, because some companies achieved certification recently. 


\section{References}

Anderson, S. W, J. D. Daly e M. F: Johnson (1999) Why Firms Seek ISO 9000 Certification: Regulatory Compliance or Competitive Advantage, Production and Operations Management, 8, $\mathrm{n}^{\circ} 1$, pp. 28-43.

Boehmer, E., J. Masumeci e A. B. Poulsen (1991), Event Study Methodology Under Conditions of Event-Induced Variance, Journal of Financial Economics, 30, pp. 253272.

Brown, Stephen J. and J. Warner (1985), Using Daily Stock Returns: The Case of Event Studies, Journal of Financial Economics, 14, pp. 3-31.

Cowan, A. R. (1992), Nonparametric Event Study Tests, Review of Quantitative Finance and Accounting, 2, Dec., pp. 343-358.

Docking, D. S. e R. J. Dowen (1999) Market Interpretation of ISO 9000 Certification, The Journal of Financial Research, 22, $\mathrm{n}^{\mathrm{o}}$ 2, pp. 147-160.

Dyckman, T., D. Philbrick e J. Stephan (1984), A Comparison of Event Study Methodologies Using Daily Stock Returns: A Simulation Approach, Journal of Accounting Research, 22, Supplement, pp. 1-33.

European Commission Survey (1997), The Added Value and Credibility of Third Party Certification of Quality Systems in The European Union, DG III Industry, Quality Series $n^{\circ}$ 5, April (Quality Policy, Certification and Conformity Marking).

Hendricks, K. B. e V. R. Singhal (1996), Quality Awards and the Market Value of the Firm: An Empirical Investigation, Management Science, 42, no 3, pp. 415-436.

ISO Survey (1999), The ISO Survey of ISO 9000 and ISO 14000 Certificates - The Eighth Cycle, International Organization for Standardization - http://www.iso.ch LRQA (1994), ISO 9000 - Setting Standards for Better Business (Lloyds Register Quality Assurance, Ltd.)

Ramasesh, Ranga V. (1998) - Baldrige Award Announcement and Shareholder Health, International Journal of Quality Science, 3, nº 2, pp. 114-125.

Romano, Pietra (2000) - ISO 9000: What is its Impact on Performance?, Quality Management Journal, 7, $\mathrm{n}^{\circ}$ 3, pp. 38-56. 
Table 1 - Sample statistics

\begin{tabular}{lccccc}
\hline & $\begin{array}{c}\text { Total Assets } \\
\text { (Mill. Esc.) }\end{array}$ & $\begin{array}{c}\text { Sales } \\
\text { (Mill. Esc.) }\end{array}$ & $\begin{array}{c}\text { Net Income } \\
\text { (Mill. Esc.) }\end{array}$ & $\begin{array}{c}\text { Market Value } \\
\text { (Mill. Esc.) }\end{array}$ & $\begin{array}{c}\text { Number of } \\
\text { Employees }\end{array}$ \\
\hline Mean & 28,237 & 18,508 & -359 & 14,726 & 890 \\
Maximum & 158,645 & 49,337 & 2,781 & 45,227 & 2,670 \\
Minimum & 6,092 & 6,193 & $-14,456$ & 5,651 & 167 \\
\hline
\end{tabular}


Table 2 - Average abnormal returns $(A A R)$ around ISO 9000 certification

\begin{tabular}{ccccc}
\hline Event Day & $\boldsymbol{A} \boldsymbol{A R}(\boldsymbol{\%})$ & $\boldsymbol{t}$-statistics & \% positive & $\boldsymbol{Z}$-statistics \\
\hline-5 & -0.250 & -1.029 & 41.7 & -0.680 \\
-4 & 0.478 & $2.804^{*}$ & 83.3 & $2.208^{*}$ \\
-3 & 0.043 & 0.172 & 58.3 & 0.475 \\
-2 & -0.090 & -0.878 & 50.0 & -0.102 \\
-1 & -0.045 & -0.307 & 41.7 & -0.680 \\
0 & 0.082 & 0.632 & 50.0 & -0.102 \\
1 & 0.148 & 0.741 & 58.3 & 0.475 \\
2 & -0.125 & -0.506 & 66.7 & 1.053 \\
3 & -0.422 & -0.996 & 41.7 & -0.680 \\
4 & 0.257 & 1.201 & 66.7 & 1.053 \\
5 & -0.022 & -0.200 & 50.0 & -0.102 \\
\hline
\end{tabular}

* Significant at the 5 percent level, two-tailed test. 
Table 3 - Cross-sectional regression of SCAAR $[-10,+1]$

\begin{tabular}{|c|c|c|c|c|c|c|}
\hline \multirow[b]{2}{*}{ Constant } & \multicolumn{3}{|c|}{ Independent Variables } & \multirow[b]{2}{*}{ F-Stat. } & \multirow[b]{2}{*}{$\operatorname{Adj} . R^{2}$} & \multirow[b]{2}{*}{$N$} \\
\hline & $L M V$ & CERT & DCERT & & & \\
\hline$-4,042$ & 0,294 & $0,152 * *$ & $0,887 *$ & $5,382 *$ & 0,544 & 12 \\
\hline$(-0,680)$ & $(0,491)$ & $(3,347)$ & $(2,447)$ & & & \\
\hline
\end{tabular}

Note: All values within brackets represent the $t$-statistic values of the corresponding coefficients ** Significant at the 1 percent level.

* Significant at the 5 percent level. 
Table 4 - Financial ratios around ISO 9000 certification

\begin{tabular}{lccccc}
\hline Ratios & year -2 & year -1 & year 0 & year 1 & year 2 \\
\hline Sales per employee ${ }^{\text {a }}$ & 17.417 & 21.794 & 24.701 & 29.723 & 31.740 \\
Sales to assets & 1.12 & 1.15 & 1.07 & 1.03 & 1.12 \\
Operating income to sales & $9.14 \%$ & $10.17 \%$ & $8.88 \%$ & $5.84 \%$ & $8.52 \%$ \\
Net income to sales & $4.88 \%$ & $4.76 \%$ & $5.57 \%$ & $3.34 \%$ & $4.94 \%$ \\
Net income to assets & $5.75 \%$ & $5.07 \%$ & $5.07 \%$ & $1.63 \%$ & $4.25 \%$ \\
Net income to shareholder's equity & $12.28 \%$ & $10.74 \%$ & $10.66 \%$ & $5.98 \%$ & $10.05 \%$ \\
\hline${ }^{a}$ Values in million of Escudos & & & & &
\end{tabular}

${ }^{\mathrm{a}}$ Values in million of Escudos 


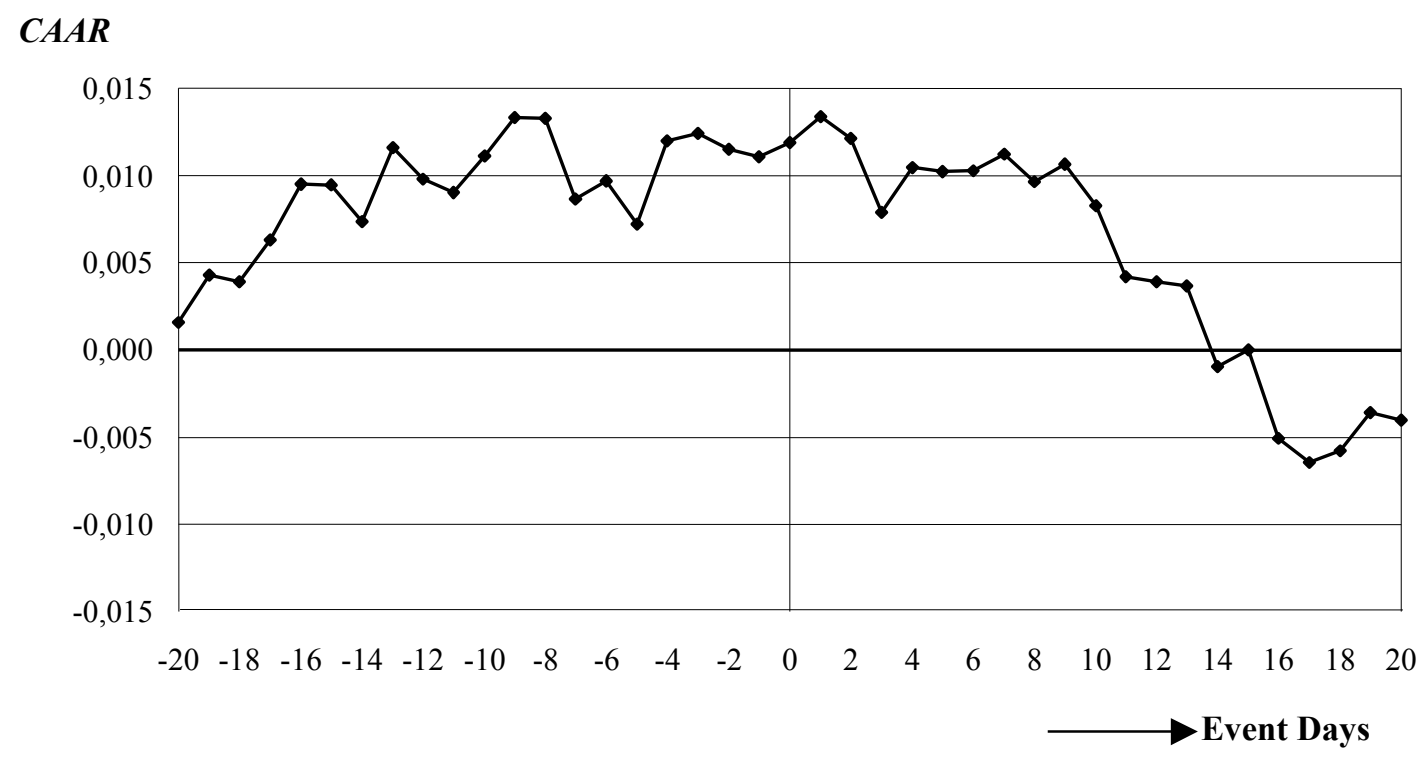

Figure 1 - Cumulative average abnormal returns from event day -20 to event day +20 


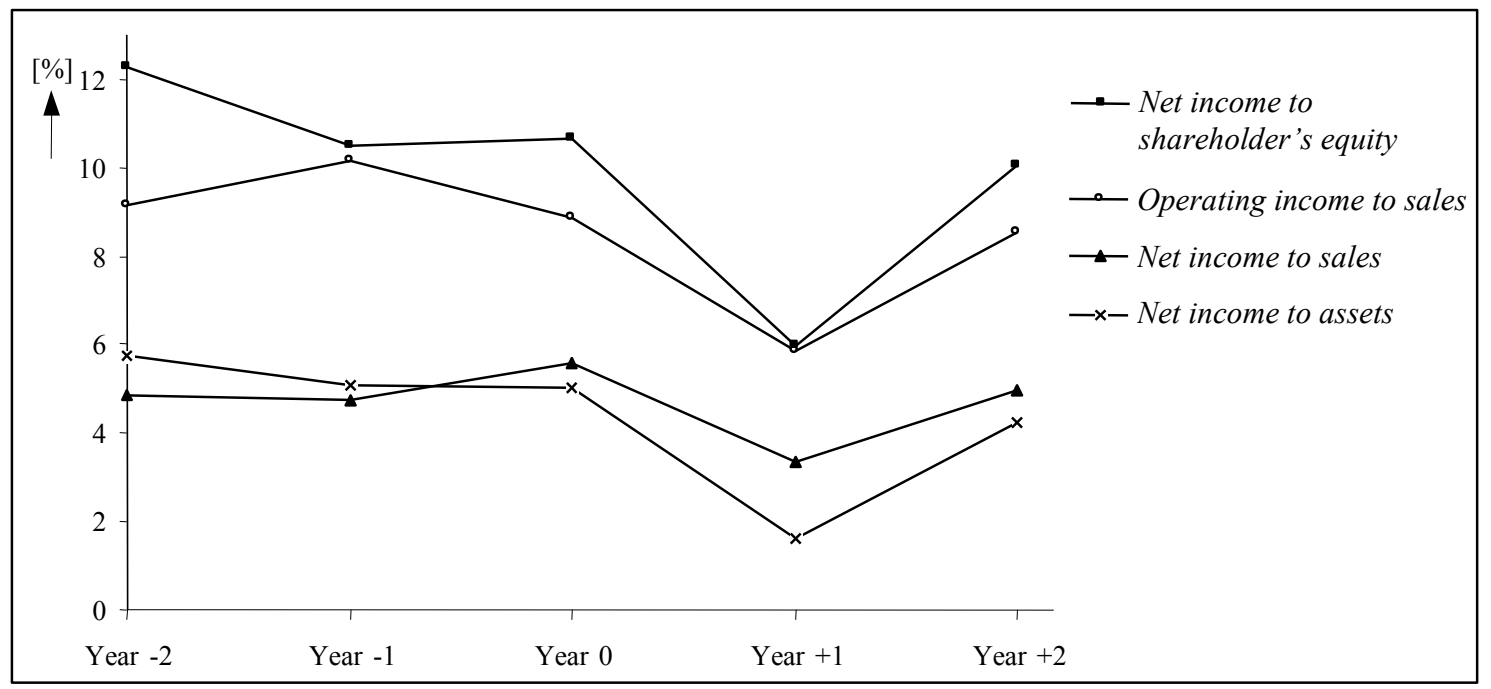

Figure 2-Evolution of the financial ratios 